Sousa, R.E,M.; Viegas, L.P. Turismo rural: uma possibilidade do novo para o assentamento Banco da Terra. Revista Brasileira de Ecoturismo, São Paulo, v.6, n.2, mai/jul-2013, pp.500517.

\title{
Turismo rural: uma possibilidade do novo para o assentamento Banco da Terra
}

\author{
Rural tourism: a possibility of the new for Banco da Terra Settlement (MT, Brazil) \\ Rúbia Elza Martins de Sousa, Luciana Pinheiro Viegas
}

\section{RESUMO}

O turismo que está se destacando no cenário econômico nacional, diante de sua capacidade de geração de trabalho e renda começa, aos poucos, a se difundir no espaço rural, especialmente em contraponto à globalização. Esse turismo se configura como uma alternativa aos agricultores de base familiar que abrem suas propriedades para um cenário mundial de competitividade, que exige produtos/serviços e estratégias empresariais compatíveis com os novos padrões vigentes. Diante disso, surge a necessidade pela busca de alternativas que garantam a sobrevivência e permanência dos agricultores familiares no meio rural sem a descaracterização enquanto espaço rural, principalmente a partir de políticas públicas que promovam o desenvolvimento racional e responsável a partir do incremento da atividade desenvolvida por esses atores. A pesquisa em tela teve o intuito de identificar as políticas públicas que otimizem a utilização da matéria-prima e recursos naturais disponíveis no Assentamento Banco da Terra, Município de Nova Xavantina, MT, de forma que os assentados busquem novas formas de utilizar os recursos locais, bem como racionalizar seu uso como fonte alternativa não-agrícola de geração de renda. A pesquisa é qualitativa e se constituiu como exploratória e descritiva. Foram utilizadas pesquisa bibliográfica, documental, além do estudo de campo com observação participante. Durante a pesquisa foram constatados problemas de ordem socioeconômica, devido à falta de efetivação de políticas públicas. Os depoimentos recolhidos por meio do procedimento de constituição de fontes orais traduzem visões particulares de processos coletivos e, dessa forma, é capaz de recuperar, de acordo com as tradições culturais do espaço rural aqui analisado, a história da luta pela conquista da terra, na perpetuação de hábitos e costumes característicos do meio rural. Portanto, o turismo rural deve ter, além de uma gestão participativa, com os próprios agricultores familiares sendo os protagonistas desse processo, deve ser ainda, desenvolvida com responsabilidade e sensibilidade para que o limite máximo de crescimento da atividade possa ser identificado antes que seja ultrapassado, o que acarretaria em impactos no meio ambiente natural, o descontentamento do público que vinha sendo contemplado e desestruturação da comunidade anfitriã.

PALAVRAS-CHAVE: Turismo; Políticas Públicas; Agricultura Familiar; Assentamento Rural. 


\section{ABSTRACT}

Tourism that has been detaching in the national economic scenario, before its ability to generate work and income, it begins gradually to spread in rural areas, especially in opposition to globalization. This tourism is configured as an alternative to family-based farmers that open their properties to a scenario of global competitiveness, which requires products / services and business strategies compatible with the new standards in vigour. Thus, there is a need to look at alternatives to ensure the survival and stableness of family farmers in rural areas, mainly from public policies that promote the rational development and responsible from the incrementation of activity developed by these actors. The screen's research aimed to identify public policies that optimize the use of raw materials and natural resources available on the Banco da Terra Settlement, in the City of Nova Xavantina, MT, so that the settlers seek new ways to use local resources and rationalize its use as an alternative source of non- agricultural income generation. This is a qualitative research and is established as exploratory and descriptive. It was used bibliographical and documental research, beyond the field study with participant observation. During the research socioeconomic problems were observed, due to lack of effective public policies. The testimonies collected by the procedure of establishment of oral sources, translates particular visions of collective processes and, thus is able to recover, according to the cultural traditions of rural areas analyzed here, the history of the struggle for land, in perpetuation of characteristic habits and customs from rural areas. Therefore, rural tourism should have, beyond a participatory management, with the farmers themselves being the protagonists of this process, should still, be developed with responsibility and sensitivity so that the growth's maximum limit of the activity can be identified before it is passed, which would result in impacts on the natural environment, public discontent that had been contemplated and disruption of the host community.

KEYWORDS: Tourism; Public Policy; Family Farming; Rural Settlement.

\section{Introdução}

A crise no meio rural para os agricultores familiares teve suas origens no Brasil na década de 1960, quando foi iniciado o processo de mecanização da lavoura, passou-se então, a utilizar insumos industrializados e as sementes passaram a ser selecionadas, visando ao aumento da produção e à consequente exportação. A modernização da agricultura brasileira teve o Estado como um grande viabilizador deste processo, pois este tinha como principal objetivo atender aos interesses dos setores mais capitalizados, os quais são refletidos no campo político, em nome da classe dos grandes proprietários rurais. Dessa forma, os agricultores familiares ficaram à margem de todas essas transformações que estavam e atualmente continuam ocorrendo no meio rural.

É nesse contexto que surge o turismo como subsídio aos agricultores familiares, no que tange à melhoria das condições de vida dos mesmos, uma vez que o tu- 
rismo é uma atividade sócio-econômica atual que gera múltiplas inter-relações, sejam elas de cunho social, cultural, econômico e ambiental.

Atualmente tem se tornado cada vez mais comum o desenvolvimento da atividade turística em áreas de assentamentos rurais, e essa prática tem auxiliado os agricultores familiares que residem nestes espaços, uma vez que estes apresentam uma série de dificuldades para se manterem no campo devido à falta de efetivação das políticas públicas voltadas ao meio rural. Sendo assim, o turismo se apresenta como atividade alternativa no meio rural.

As políticas públicas voltadas para o espaço rural tem a função de orientar os agricultores familiares, quanto às formas mais eficazes de produção, porém, a falta de efetivação destas políticas tem prejudicado a produção rural, uma vez que os produtores familiares ficam desprovidos de incentivos financeiros, técnicos e governamentais para produzir.

Diante disso, este trabalho foi desenvolvido no Assentamento Banco da Terra, localizado no Município de Nova Xavantina, Estado de Mato Grosso, distante $12 \mathrm{Km}$ do núcleo urbano, com acesso pavimentado e teve o intuito de identificar as ações de políticas de ordenamento territorial rural que otimizem a utilização da matéria-prima e dos recursos naturais disponíveis no agroecossistema do Assentamento, de maneira que os agricultores familiares possam buscar novas formas de utilização dos recursos locais, bem como racionalizar seu uso como fonte alternativa não-agrícola de geração de renda, como o turismo, por exemplo, aqui enfocado. Para que este objetivo fosse alcançado, fez-se necessário identificar as políticas públicas voltadas para a agricultura familiar e as direcionadas para o turismo rural na agricultura familiar; averiguar as políticas públicas que foram e que estão sendo desenvolvidas no Assentamento Banco da Terra; bem como estudar as formas de acesso a estas políticas por parte dos agricultores familiares que residem na localidade.

Esta pesquisa tem uma abordagem qualitativa utilizando-se de pesquisa bibliográfica, documental e estudo de campo com observação participante. Estes procedimentos utilizados para 0 alcance dos objetivos propostos possibilitaram aproximação conceitual para analisar os fatos do ponto de vista empírico, de forma a confrontar a visão teórica com a realidade. Foram realizadas entrevistas não-diretivas junto a trinta assentados e ao poder público do município, dentre eles a responsável pela Divisão de Turismo da Secretaria de Turismo e Meio Ambiente, o chefe da Divisão de Assistência e Produção e o Presidente do Sindicato dos Trabalhadores Rurais. Estas entrevistas foram gravadas, transcritas e analisadas posteriormente.

Este trabalho inicia-se com uma retomada de diferentes abordagens de concepções e discussões sobre turismo rural e agricultura familiar, seguida de contextualização histórica sobre os assentamentos rurais e a luta pela terra no Brasil para posterior apresentação, de forma sucinta, das políticas públicas voltadas para a agricultura familiar e para o turismo rural neste segmento, sendo estas políticas selecionadas de acordo com o tema proposto por este trabalho. 


\section{Como fazer diferente: o turismo frente à agricultura familiar}

A atividade turística tem sido um importante agente de revitalização cultural e ambiental de territórios ${ }^{1}$ brasileiros uma vez que, esta atividade se vale de tais aspectos como atrativo, e por este motivo há a preocupação em resgatar, conservar, bem como valorizar os mesmos, para que assim possam ser utilizados de forma racional. O turismo tem atingido até mesmo territórios situados no meio rural, valendo-se dessa forma, da singularidade destes locais como atrativo turístico.

Em uma época de transformações nos modos de produção, em que os recursos estão cada vez mais escassos e a concorrência de produtos estrangeiros é algo real, os agricultores familiares tem encontrado dificuldades em dar continuidade ao desenvolvimento de atividades de cunho agrícola e/ou agropecuária em sua propriedade (VIEGAS, 2006).

Dessa forma, os problemas que tem ocorrido no campo, tem como grande consequência o movimento campo-cidade, principalmente por parte dos agricultores familiares, que se veem impossibilitados de continuar no meio rural, pela falta de condições financeiras para suprir necessidades basilares de suas famílias. Sendo assim, os agricultores migram para os grandes centros urbanos, passando a agravar as estatísticas de desemprego, vivendo sob condições marginais. E neste contexto que o turismo rural surge como uma importante alternativa de complementação da renda agrícola, da elevação da auto-estima destes sujeitos sociais, além de contribuir para sua fixação no campo.

De acordo com Dinis (2011, p.30) turismo rural "[...] inclui a cultura como parte integrante do produto e caracteriza-se por um contato personalizado, integração no ambiente físico e humano e a participação na forma de vida da comunidade".

Neste sentido o turismo rural possui uma vertente cultural que perpassa intimamente por questões relacionadas à representação e ao simbolismo que o turista cria frente ao espaço rural e ao que permeia o desenvolvimento da atividade turística neste. Esta vertente pode ser caracterizada pelo contato do turista com aquilo que intenciona a singularidade, pois há - mesmo que inconscientemente - a necessidade de vivenciar a vida do 'outro', de se colocar no lugar deste 'outro'.

Atrelado às questões culturais e de representação do espaço rural para o turista, encontra-se a vertente econômica, uma vez que o meio rural tem se mostrado cada vez mais produtivo para a implantação de novas atividades voltadas para o viés econômico, isto não pode ser ignorado.

Sendo assim, a atividade turística é desenvolvida como forma de valorização das famílias que vivem em territórios rurais, por meio de atividades relacionadas à produção, lazer, esporte, gastronomia, dentre outros. Salienta-se que o turismo rural deve ser de caráter apenas complementar, uma vez que a atividade tradicional deve continuar sendo praticada pelos agricultores familiares como atividade principal na unidade de produção, pois como afirmam Almeida e Riedl (2000, p.11) "[...] o turista aprecia participar ativa ou passivamente do trabalho na agricultura e adora saber que a maioria dos produtos consumidos nas refeições provém do estabelecimento visitado".

A agricultura familiar é conceituada por Viegas (2007, p.4 e 5) como "[...] àquela 
em que os trabalhos ao nível da unidade de produção são exercidos predominantemente pela família, mantendo ela a iniciativa, o domínio e o controle, do 'que' e do 'como' produzir'. É importante que haja uma estreita relação entre o que é produzido e o que é consumido. Sendo assim, na agricultura familiar o trabalho conjunto dos membros da família, objetivando o sustento coletivo integra os laços consanguíneos à esfera da produção.

Segundo Schneider (2003), a expressão "agricultura familiar" teve destaque no contexto brasileiro na metade da década de 1990 paralelamente à efervescência dos movimentos sociais no campo comandados pelo sindicalismo rural ligado à Confederação Nacional dos Trabalhadores na Agricultura - Contag. Mesmo diante de desafios como a falta de crédito agrícola e queda dos preços dos principais produtos agrícolas que eram exportados, a agricultura familiar mostrou-se capaz de oferecer proteção a um conjunto de categorias sociais compostas por assentados, arrendatários, parceiros, integrados à agroindústria, dentre outros.

A agricultura familiar atualmente possui uma grande representatividade, especialmente em 2006 quando foi sancionada a Lei 11.326 de 24 de julho que "estabelece conceitos, princípios e instrumentos destinados à formulação das políticas públicas direcionadas à agricultura familiar e empreendimentos familiares rurais" (BIANCHINI, 2005, p.83), oferecendo garantias de direito à elaboração de políticas de ordenamento territorial rural já que no Brasil existem 4.859.864 estabelecimentos rurais, que ocupam uma área de 353,6 milhões de hectares, os agricultores familiares totalizam 4.139.369 (85,5\%), ocupando uma área de 107,8 milhões de hectares. Faz-se necessário ressaltar ainda que a agricultura familiar é responsável por $70 \%$ da produção de alimentos no Brasil, sendo a base econômica de cerca de $90 \%$ dos municípios e respondendo por $35 \%$ do PIB nacional abrigando, dessa forma, $40 \%$ da população economicamente ativa (ROSA, 1999).

A produção familiar na agricultura, mesmo diante das adversidades e transformações que tem ocorrido pelo advento do capitalismo, tem mostrado a força do caráter familiar e sua representatividade nos setores social e econômico do país. Um exemplo bem prático é o que está acontecendo em áreas de assentamentos rurais, pois, sem condições adequadas para o trabalho e sem infra-estrutura de apoio aos assentados, vem surgindo em meio a esses obstáculos as atividades não-agrícolas, a exemplo dos setores de serviços como a atividade turística, que vem, sobretudo para valorizar as potencialidades naturais e culturais existentes no espaço rural.

\section{Assentamentos rurais: a luta pela terra}

As disputas pelo acesso à terra no Brasil remontam a forma de como se deu a colonização de seu território, uma vez que Portugal colonizou o país por meio da criação de grandes unidades produtivas, fato que determinou o modo de apropriação das terras do Brasil, sendo que esse é caracterizado por grandes fazendas, com base no uso de mão-de-obra em abundância.

No Brasil em meados do século XIX iniciaram-se, no Parlamento, algumas discussões relacionadas à divisão de terras, predominando os grandes latifundiários. Como 
resultado de toda essa polêmica em torno da apropriação e do uso de terras, surgiu a Lei de Terras, aprovada em 1850, esta segundo Coelho (2002, p. 22) "[...] redefiniu o acesso à terra, restringindo-o a quem tinha poder aquisitivo para adquiri-la mediante compra". Observa-se então, que a Lei de Terras garantia mecanismos que tornaram possível a manutenção de grandes unidades de produção e da disponibilidade de mãode-obra.

De acordo com Medeiros (2003, p.16), a reforma agrária "[...] era definida como a divisão das grandes propriedades entre as quais nela quisessem trabalhar e a consequente extinção dos latifúndios". Essa medida seria o primeiro passo a um modelo de desenvolvimento, uma vez que promoveria o crescimento acelerado das forças produtivas do campo, visto que os trabalhadores rurais estavam vivendo em situação de exploração e miséria, o que os impedia de constituírem-se em mercado consumidor dos produtos industrializados que estavam sendo produzidos no país.

Em meados dos anos 1990, no início do primeiro mandato do presidente Fernando Henrique Cardoso, a temática agrária tinha perdido seu lugar nos debates políticos, mas dois fatos que ocorreram trouxeram à tona as questões agrárias, sendo eles: a extrema violência policial em relação às ações de trabalhadores rurais, fato que foi evidenciado nos massacres ocorridos em Corumbiara e em Eldorado dos Carajás; a retomada das ocupações de terra pelo Movimento dos Trabalhadores Sem Terra (MST) e por outras entidades ligadas à luta pela terra (MEDEIROS, 2003).

De volta às pautas do Governo, os trabalhadores conquistaram outras políticas que culminaram no programa "Agricultura familiar, reforma agrária e desenvolvimento local para o novo mundo rural" (MEDEIROS, 2003, p.56). Este objetivava o desenvolvimento rural com base na expansão da agricultura familiar e sua inserção no mercado, e tinha como lema 'Levar qualidade aos assentados', tratando estes como agricultores familiares e traçando uma programação de ações junto aos mesmos.

Ao longo das últimas duas décadas, consequência dos diversos anos de luta pela terra e da crescente organização dos trabalhadores com movimentos de resistência assumiram a posição de "sem-terra", surgiram os assentamentos rurais. Tal denominação nomeia uma série de ações governamentais que envolvem a atribuição de terras a trabalhadores rurais.

Bergamasco e Norder (1996), afirmam que assentamentos rurais são ações de novas unidades de produção agrícola, criados por meio de políticas governamentais, que visam ao reordenamento do uso da terra, de forma que beneficie trabalhadores rurais com pouca ou nenhuma terra.

Diante do "inchaço" populacional dos grandes centros urbanos, os assentamentos rurais, surgem como alternativa de emprego e moradia, estabelecendo assim um modelo de desenvolvimento agrícola mais justo e equitativo. No entanto, grande parte dos assentamentos foi criado sem planejamento necessário, de forma que ficaram distribuídos em espaços consentidos pelo latifúndio. Com a dispersão nos assentamentos houve dificuldade em se potencializar infraestrutura necessária ao seu desenvolvimento. É comum encontrar assentamentos onde o acesso é precário, prejudicando o escoamento de produtos e até mesmo o deslocamento dos assentados para o centro urbano de onde ainda dependem de alguns serviços. 
Apesar de todas as dificuldades enfrentadas pelos trabalhadores que residem em áreas rurais, o turismo vem objetivando trazer impactos socioeconômicos positivos a esta população, uma vez que a atividade turística desenvolvida nestas localidades tem como uma das principais propostas a complementação da renda e a valorização do espaço vivido.

A atividade turística, quando realizada no meio rural, além de valorizar os aspectos naturais e culturais, estimula e recupera a conservação da economia das regiões envolvidas. A partir de então, passa a existir dinamização da cultura rural e, concomitante a conservação da identidade e autenticidade, de forma a resgatar os valores, os costumes, a história do local, transformando assim, em atrativos típicos e utilizados como representações simbólicas.

O turismo rural é um grande agente promotor, visto que é atividade estratégica, no que tange à mobilização, diversificação da economia local, promoção socioeconômica e a revitalização ambiental, sendo assim, a atividade turística contribui para implementação das estruturas básicas no meio rural (ARAÚJO, 2000). Dessa forma, esta atividade garante a manutenção de atividades agrícolas e, como consequência, mantêm a família rural no campo e formula um novo conceito de produção, devido ao incremento da receita da comunidade rural.

A atividade turística quando desenvolvida em assentamentos rurais apresenta impactos positivos aos assentados, como auxílio à permanência destes na unidade de produção familiar, pois com as dificuldades que tem enfrentado em permanecer no campo, o desenvolvimento do turismo se transforma em apoio aos agricultores, proporcionando continuidade dos mesmos no meio rural; o romper do isolamento dos agricultores, uma vez que a atividade turística proporcionará maior contato com pessoas de lugares diferentes, podendo haver, assim, a troca de experiências e informações; a diversidade de produtos e serviços ofertados, em que os assentados deverão diversificar a produção para atender, depois de supridas as suas, as necessidades dos turistas que visitarão suas propriedades, inserindo o turismo na multifuncionalidade e pluriatividade do espaço rural.

Para que ocorra melhoria na qualidade de vida dos agricultores dos assentamentos, são necessárias políticas que promovam desenvolvimento responsável no meio rural, a partir da implantação e desenvolvimento da atividade por parte dos agricultores familiares.

\section{Revisitando as políticas públicas direcionadas à agricultura familiar}

De acordo com Holanda (1975, p.1109), política é definida como "ciência dos fenômenos referentes ao Estado, sistemas de regras, [...] arte de bem governar, conjunto de objetivos, princípios doutrinários, posição ideológica, habilidade no trato das relações humanas". Dessa forma, a política é um meio de gerenciar os interesses da coletividade, sendo que estes devem estar em consonância e em torno de um objetivo comum. 
Valendo-se disso, deve-se ressaltar que a política pode e deve ser flexível e dinâmica, tanto no processo de formulação quanto no de implantação, devendo estar adequada aos interesses e a realidade de cada comunidade.

As políticas públicas direcionadas à agricultura familiar devem fornecer orientações necessárias aos agricultores familiares, no que tange às formas mais adequadas de produção, bem como meio financeiro e técnico para que os agricultores produzam. As políticas de turismo rural voltadas para a agricultura familiar visam ao desenvolvimento rural racional, por meio da implantação e fortalecimento das atividades turísticas pelos agricultores familiares, de forma a otimizar sua produção, gerando postos de trabalho e com consequente melhoria das condições de vida rural.

Na sequência serão citadas e brevemente comentadas algumas ações de políticas públicas direcionadas à agricultura familiar, focalizando aquelas voltadas para o desenvolvimento da atividade turística.

\section{Territórios da cidadania}

O Programa Territórios da Cidadania é resultado do esforço do Governo Federal para priorizar ações em regiões e sub-regiões, onde os investimentos públicos e privados não tem sido suficientes para atender às necessidades basilares da população. Ele objetiva superar a pobreza e as desigualdades sociais no meio rural inclusive as desigualdades de gênero, raça e etnia, por meio de estratégia de desenvolvimento territorial sustentável.

De acordo com o MDA esta política visa promover articulação e gestão de forma descentralizada e participativa, onde serão priorizadas ações para alcançar o desenvolvimento social, de forma a apoiar e fortalecer os territórios, no que tange à capacidade social de autogestão dos processos de promoção do desenvolvimento das populações que vivem em territórios rurais, possibilitando que os próprios agricultores familiares protagonizem as iniciativas.

Para seleção e posterior definição dos territórios de Ação Integral são utilizados alguns parâmetros, dentre eles: territórios com maior concentração de beneficiários do Programa Bolsa Família; territórios com menor IDH; territórios com maior número de municípios com baixo dinamismo econômico; dentre outros (MINISTÉRIO DO DESENVOLVIMENTO AGRÁRIO, s/d).

Essas políticas com vistas à redução das desigualdades regionais em muito precisam avançar no sentido de dar, efetivamente, autonomia aos trabalhadores rurais, representados por associações, sindicatos ou outras formas organizativas, pois, da forma como estão sendo elaboradas, só legitimam o discurso hegemônico de que as políticas são oferecidas, porém não são elaborados projetos por parte dos agricultores para captar os recursos disponibilizados. 


\section{Política nacional de assistência técnica extensão rural}

A Política Nacional de Assistência Técnica e Extensão Rural (PNATER) tem como objetivo contribuir para uma ação institucional que seja capaz de implantar e consolidar estratégias de desenvolvimento rural, de forma a estimular a geração de renda e de novos postos de trabalho. Para tanto, potencializa atividades produtivas agrícolas voltadas à oferta de alimentos e, apóia estratégias de comercialização destes alimentos produzidos tanto nos mercados locais como nos mercados regionais e internacionais. Igualmente, deve estimular outras formas de agregação de renda à produção primária, assim como o desenvolvimento de atividades rurais não-agrícolas (BRASIL, 2007).

Esta política prevê que os serviços públicos de assistência técnica e extensão rural (Ater) sejam executados por meio do uso de metodologias participativas, onde seus agentes desempenharão papel educativo, atuando como facilitadores de processos de desenvolvimento rural. Ao mesmo tempo, as ações de Ater devem privilegiar o potencial endógeno das comunidades, de forma a resgatar e interagir com os conhecimentos dos agricultores familiares, estimulando o uso racional dos recursos locais.

\section{Programa nacional de crédito fundiário}

O Programa Nacional de Crédito Fundiário é desenvolvido pelo Ministério de Desenvolvimento Agrário desde 2003 e é voltado para os agricultores familiares, uma vez que objetiva trazer condições aos agricultores sem terra ou com pouca terra para que estes possam comprar um imóvel rural por meio de financiamento. Este financiamento pode ser utilizado para criação da infraestrutura necessária para produção técnica e extensão rural, para estruturar a moradia dos agricultores, adquirir implementos, enfim, tudo o que for necessário para que os mesmos possam se desenvolver de forma autônoma.

O público do PNCF é composto por agricultores rurais sem terra, arrendatários, parceiros, meeiros, posseiros e proprietário de terra cuja dimensão é inferior ao módulo rural. O potencial beneficiado deve ter, no mínimo, cinco anos de experiência no meio rural nos últimos 15 anos. É importante mencionar que o Programa prevê ações de estímulo às mulheres, jovens e negros que vivem em territórios rurais (BRASIL, s/ d).

\section{Programa nacional de fortalecimento da agricultura familiar}

O Programa Nacional de Fortalecimento da Agricultura Familiar (PRONAF) constitui-se no primeiro e mais importante exemplo de política setorial diferenciada, voltada para a agricultura e para o mundo rural brasileiro. Este programa vem refletindo a emergência de preocupações relacionadas ao meio ambiente, à sustentabilidade e às diversas questões do desenvolvimento do meio rural.

De acordo com o MDA, o PRONAF "financia projetos individuais ou coletivos, 
que gerem renda aos agricultores familiares e assentados da reforma agrária". O Programa concede crédito para custeio da safra, atividade agroindustrial, investimento em máquinas, equipamentos e infraestrutura de produção e serviços agropecuários ou não-agropecuários.

O PRONAF oferece várias linhas de crédito, ligadas aos mais diversos setores que englobam o meio rural, pode-se citar algumas destas: a) Custeio, financiamento destinado a atividades agropecuárias e de beneficiamento; b) Pronaf investimento, crédito voltado para a ampliação ou modernização da infraestrutura de produção e serviços; c) Pronaf agroecologia, linha de financiamento para investimentos dos sistemas de produção agroecológicos ou orgânicos; d) Pronaf eco, financia investimentos em técnicas que minimizam o impacto negativo da atividade rural ao meio ambiente; dentre outros.

Os agricultores familiares que desejam obter financiamento por meio do Pronaf, devem seguir alguns passos para acessar às linhas de crédito do Programa, sendo eles: a decisão familiar pela busca do crédito, momento onde a família deverá decidir conjuntamente o projeto a ser desenvolvido dentro da propriedade; o segundo passo é saber em qual grupo e qual linha do Pronaf o agricultor se encontra, para tal este deve requerer a Declaração de Aptidão ao Pronaf- DAP, documento este que é fornecido gratuitamente por órgãos públicos e entidades de classe credenciados pelo MDA; de posse da DAP o agricultor deve procurar um orgão estadual responsável pela assistência técnica e extensão rural para elaboração de projeto técnico, neste constará o valor e a época de todas as despesas relativas ao projeto; por fim, um agente financeiro deve ser procurado, para que a solicitação do financiamento seja feita (SEBRAE, s/d).

Nota-se, quanta burocracia é exigida do agricultor para que o mesmo tenha acesso aos financiamentos via Pronaf. Dessa forma, muitos deles se veem impossibilitados de acessarem a estes financiamentos, devido à falta de informações básicas necessárias, bem como por não saber a que orgão recorrer para se informar sobre os documentos requeridos para aquisição do crédito.

\section{Terra sol}

O Terra Sol tem como objetivo proporcionar o aumento de renda dos Projetos de Assentamentos da reforma agrária, através de atividades socioeconômicas que valorizem as características regionais, experiências e, potencialidades locais, com destaque na Agroecologia.

A política Terra Sol contempla, em princípio, qualquer negócio, desde que possibilite a agregação de renda para os assentados e esteja dentro das seguintes linhas: agroindustrialização, comercialização, atividades pluriativas e agroecologia. É importante salientar que são priorizados aqueles negócios nos quais se utilize matériaprima do próprio assentamento, que trabalhe o desenvolvimento racional dos recursos locais, a agroecologia e que tenha a participação do maior número de famílias de assentados, incluindo a mulher e o jovem. 


\section{Programa nacional de turismo na agricultura familiar}

O Programa Nacional de Turismo Rural na Agricultura Familiar (PNTRAF) é resultado de parceria firmada entre o Ministério do Turismo e o Ministério de Desenvolvimento Agrário, e tem como principais princípios: a prática do associativismo; a valorização e o resgate do patrimônio cultural e natural; a inclusão dos agricultores familiares, respeitando as relações de gênero, raça e etnia; a manutenção do caráter complementar dos produtos e serviços do turismo rural na agricultura familiar; o comprometimento com a produção agropecuária de qualidade e com os processos agroecológicos; a compreensão da multifuncionalidade da agricultura familiar em todo o território nacional (BRASIL, s/d).

O PNTRAF tem como objetivo promover o desenvolvimento rural sustentável, a partir da implantação e fortalecimento das atividades turísticas pelos agricultores familiares, integrado aos arranjos produtivos locais, de forma a agregar renda e gerar postos de trabalho no meio rural, com consequente melhoria das condições de vida (BRASIL, s/d).

O Programa beneficia produtores familiares tradicionais, assentados por programas de reforma agrária, extrativistas florestais, ribeirinhos, indígenas, quilombolas, pescadores com métodos artesanais, povos da floresta, seringueiros e suas organizações.

\section{Fomento ao turismo rural na agricultura familiar: Rede TRAF}

Este trabalho não poderia deixar de mencionar, a Rede de Turismo Rural na Agricultura Familiar (Rede TRAF), sendo esta um grupo de discussões que levanta as principais demandas de políticas públicas no meio rural voltadas para o turismo rural. Esta Rede é uma união entre técnicos, instituições e representações de agricultores familiares, que tem em vista desenvolver o turismo rural na agricultura familiar no Brasil, com objetivo de realizar um turismo racional em território rural, através do fortalecimento da atividade turística pelos agricultores familiares.

A Rede TRAF traçou alguns objetivos a serem atingidos em relação ao desenvolvimento do turismo no meio rural, dentre eles destacam-se: debater questões proeminentes para o desenvolvimento do turismo rural na agricultura familiar; auxiliar o poder público na definição de políticas públicas; fomentar o intercâmbio de experiências entre os atores envolvidos no desenvolvimento da atividade turística (BRASIL, s/d).

Dessa forma, a Rede TRAF é uma importante aliada do Governo, no que tange ao desenvolvimento do turismo rural na agricultura familiar, uma vez que esta organização vem apoiar tecnicamente os orgãos governamentais que tem ações de planejamento para desenvolver o TRAF.

Contudo, a atividade turística, ao ser desenvolvida em propriedades rurais, é 
vista como fator importante para a complementação da renda das famílias agricultoras e como uma atividade capaz de agregar valor ao meio rural. Sendo assim, as políticas públicas de turismo voltadas para a agricultura familiar fomentam o desenvolvimento da atividade de forma racional, uma vez que objetivam fortalecer as atividades turísticas desenvolvidas nas propriedades rurais, bem como agregar valor ao meio rural e às práticas rurais desenvolvidas nas unidades de produção.

\section{Área de estudo}

O Assentamento Banco da Terra, objeto deste estudo, está localizado na Região do Médio Araguaia, Estado de Mato Grosso, Município de Nova Xavantina, distante $12 \mathrm{~km}$ da sede, sendo a BR 158 a via de acesso ao local. É composto por sessenta famílias em sua formação, totalizando sessenta lotes com uma família em cada, em uma área total de aproximadamente 570 hectares, tendo cada parcela, 8.9 hectares. As parcelas estão distribuídas ao longo de uma estrada que passa por todo o assentamento, sendo assim, trinta lotes se encontram do lado direito e os outros trinta do lado esquerdo da estrada.

Este Assentamento faz parte da política pública de Crédito Fundiário criada pelo Governo Federal em 1998, esta política era anteriormente denominada de Banco da Terra, denominação esta que originou o nome do assentamento estudado.

Os agricultores familiares desenvolvem, no interior das unidades produtivas, atividades prioritariamente de caráter agropecuário, dentre as realizadas pode-se citar criação de gado leiteiro e pequenos animais (suínos, caprinos, ovinos e aves); cultivo de melancia, milho, cana, laranja, mandioca, hortaliças, dentre outras. É importante mencionar que a produção interna não tem sido suficiente para suprir as necessidades básicas de famílias residentes na localidade, de forma que os assentados tem buscado emprego externo às propriedades, como no Frigorífico, sendo esta a principal opção de emprego para estes assentados, uma vez que está localizado próximo ao assentamento.

Na tentativa de manter uma relação com os núcleos urbanos do entorno, o que é fundamental para gerar fluxo turístico no local, pode-se destacar duas cidades de pequeno porte, Nova Xavantina, que já foi citada, e, Água Boa, distante $84 \mathrm{Km}$, com estrada pavimentada. Esta cidade foi resultado do avanço da fronteira agrícola da região Sul, com costumes característicos da cultura gaúcha, porém, tem pouco conhecimento das atividades desenvolvidas no Banco da Terra.

\section{Discutindo resultados}

Diante da pesquisa realizada foi constatado que todos os agricultores do Banco da Terra tiveram acesso a, pelo menos, duas políticas públicas, sendo elas: a política do Banco da Terra, hoje denominada de Crédito Fundiário, e o Pronaf. A primeira está relacionada ao financiamento para compra da terra; e a segunda ao financiamento cedido para desenvolvimento de atividades voltadas à agricultura e à suinocultura. Interessante destacar que a política de Crédito Fundiário impossibilitava a venda do 
imóvel rural, uma vez que ele fosse financiado, mas a cláusula desta política não foi obedecida por vários dos agricultores, o que vai ao encontro da realidade nacional de forma que, alguns deles, vendo-se impossibilitados de manter-se no campo, venderam suas parcelas, migrando para a cidade, e assim, as dívidas com os financiamentos relativos às políticas públicas passaram a ser responsabilidade do novo posseiro da terra.

Dessa forma, como afirma Viegas (2006, p.6), a "Agricultura Familiar apresenta uma realidade de muitas dificuldades para os agricultores brasileiros, com constantes migrações [...] em busca de melhorias na qualidade de vida". Esta realidade apresentada pela autora pode ser notada no assentamento estudado, em que agricultores familiares enfrentam dificuldades socioeconômicas pelo fato de estarem com dívidas relativas à aquisição de financiamentos, o que os impedem de adquirir novos financiamentos para desenvolverem atividades de cunho agropecuário e nãoagropecuário dentro da unidade produtiva.

Com a pesquisa, pode-se constatar que alguns agricultores familiares tem dificuldade para pagar as parcelas dos financiamentos, os mesmos tentam justificar dizendo que estas são muito caras, não condizendo dessa forma, com a renda mensal das famílias que não recebem assistência técnica. Sendo assim, nos anos de 2006, 2007 e 2008 as parcelas do Pronaf ficaram sem ser pagas por todos os agricultores associados à Associação Deus é Amor, mas esta dívida foi renegociada, de forma que os assentados pagaram apenas um por cento (1\%) da dívida total. Hoje, apenas dois assentados desta Associação estão inadimplentes com as parcelas do Pronaf. Referente à Associação Vale do Araguaia salienta-se que todos os associados estão em situação de adimplência com as parcelas do Pronaf.

Foi verificado que atualmente, todos os agricultores da Associação Deus é Amor estão adimplentes com as parcelas do Crédito Fundiário, porém, os agricultores familiares que fazem parte da Associação Vale do Araguaia estão inadimplentes, pois não pagaram nenhuma das parcelas referentes a este financiamento.

De acordo com Medeiros (2003), grande parte dos assentamentos rurais no Brasil, foram construídos sem a mínima infraestrutura necessária para seu desenvolvimento, uma vez que há grande precariedade em termos de serviços de saúde, educação, saneamento básico, entre outros. Dessa forma, a pesquisa pode averiguar que no Assentamento Banco Terra a realidade não é diferente, uma vez que o local não possui estrutura básica para seu desenvolvimento, pois ainda não foram desenvolvidas ações de políticas públicas voltadas para a infraestrutura de saneamento básico, saúde e lazer. Essas questões são vitais para a boa qualidade de vida da comunidade, bem como para o bom andamento das atividades desenvolvidas no assentamento.

Foi averiguado que dos trinta agricultores entrevistados, vinte e oito deles se interessam em obter acesso a alguma política pública de crédito, voltada para o desenvolvimento da atividade turística, porém, até o momento o município, que foi solicitado, manifestou somente verbalmente interesse em desenvolver. Foi mencionado 
por eles que seria interessante desenvolver o turismo na localidade, pois a atividade seria um complemento à renda familiar, além do que haveria a valorização dos aspectos culturais e produtivos, uma vez que o turismo proporcionaria o contato de turistas interessados em conhecer os costumes e os modos de produção da localidade visitada. Esta expectativa dos agricultores familiares fica evidenciada, uma vez que o Ministério de Desenvolvimento Agrário (s/d), afirma que a atividade turística apresenta uma característica transdisciplinar e multissetorial, permitindo a valorização da cultura e da atividade produtiva das comunidades familiares, além de estimular a recuperação e conservação da economia da localidade.

Segundo Mattei (2001), o Pronaf apresenta problemas na sua operacionalização, devido à exagerada burocracia necessária para ter acesso aos recursos financeiros. Durante a pesquisa pode-se verificar as dificuldades que os agricultores familiares encontram para acessar às linhas de crédito do Pronaf, visto que os procedimentos são um tanto quanto burocráticos, dificultando aos agricultores acessarem com maior facilidade estas ações de políticas públicas voltadas para a agricultura familiar.

A chefe da Divisão de Turismo da Secretaria de Turismo e Meio Ambiente quando questionada acerca do desenvolvimento de políticas públicas voltadas para o turismo rural no Assentamento Banco da Terra, respondeu que ainda não existe nenhuma política pública para o desenvolvimento do turismo rural na localidade, pois a Secretaria está focada primeiramente na melhoria da infraestrutura da cidade, para receber turistas. Mas foi mencionado que futuramente existem planos para o desenvolvimento do turismo rural no local, visto que a demanda existente ainda é pouco significativa no assentamento, fruto do beneficiamento da produção local e confecção de artesanatos, além do ponto positivo da localização do assentamento, às margens da BR-158, caracterizado por grande fluxo de viajantes que, muitas vezes, realizam uma parada para aquisição de produtos expostos em quitandas às margens desta BR ou simples conversa ao sentar para "tomar um cafezinho" com os moradores, muito conhecidos na região.

Durante a pesquisa, foi constatado que o município de Nova Xavantina não possui Secretaria de Agricultura, o que dificulta o desenvolvimento de políticas públicas em nível municipal voltadas para a agricultura e pecuária no Assentamento Banco da Terra. Há apenas um chefe da Divisão de Assistência e Produção que responde a questões que competiriam ao Secretário de Agricultura.

Dessa forma, o chefe da Divisão de Assistência e Produção, bem como o Presidente do Sindicado dos Trabalhadores Rurais foram questionados sobre o desenvolvimento de políticas públicas municipais no Assentamento Banco da Terra, sendo assim suas respostas foram bem similares, afirmando que na localidade é muito complicado desenvolver algum programa do governo, uma vez que muitos assentados estão inadimplentes com as dívidas dos financiamentos, fato que os impossibilita de requererem novas fontes de crédito para o desenvolvimento de atividades agropecuárias. Em relação à merenda escolar, foi perguntada qual estratégia será utilizada para que os agricultores familiares comercializem seus 
produtos para as escolas, uma vez que é lei, no mínimo, trinta por cento da merenda escolar deve ser advinda da agricultura familiar; os secretários responderam que já foi feita uma reunião com a Secretaria de Educação do município para que as escolas passem a comprar os produtos dos agricultores familiares, porém, estes não tem produção suficiente para atender as escolas. Ressalta-se ainda, que alguns agricultores familiares já forneceram leite para escolas, mas a vigilância sanitária proibiu este comércio, pelo fato de que o leite, para ser fornecido a estes estabelecimentos, deve ser pasteurizado, procedimento este, pelo qual o leite não estava sendo submetido quando comercializado pelos agricultores familiares.

Contudo, os resultados encontrados caminham no sentido de que há uma necessidade constante de se criar políticas públicas para o desenvolvimento de atividades ligadas à produção rural, ação que garanta a permanência destes agricultores na terra e, com isso, outras atividades possam ser agregadas àquelas existentes para o desenvolvimento da atividade turística no meio rural, desejo dos agricultores familiares consultados nas pesquisas.

\section{Conclusão}

Nota-se claramente que os agricultores familiares do Assentamento Banco da Terra, tem sofrido com a atual situação em que vivem, uma vez que são obrigados a pagar os financiamentos adquiridos, sem condições, visto que a produção familiar dentro da propriedade tem sido muitas vezes insuficiente para o sustento da família. Em relação aos órgãos públicos pode-se verificar que estes preferem se isentar e não desenvolver qualquer tipo de atividade no local devido à situação em que se encontra a comunidade, fato que se dá pelas inadimplências dos assentados em relação ao pagamento dos financiamentos, problemas relacionados à escritura das parcelas, e mesmo a falta de interesse dos próprios agricultores em procurar soluções para a melhoria da qualidade de vida, bem como da produção junto a esses órgãos.

Verifica-se que, atualmente, os agricultores familiares do Assentamento Banco da Terra estão preocupados primeiramente em desenvolver de forma mais adequada e produtiva, as atividades agropecuárias, uma vez que os mesmos tem encontrado problemas com a produção, devido à falta de incentivo técnico e financeiro para produzir.

Por fim, analisando a atual situação em que se encontram os agricultores familiares do Assentamento Banco da Terra, a atividade turística poderia auxiliar os assentados no que tange à questão econômica, em um primeiro momento, o que explica a ênfase dada a esta dimensão ao longo do artigo, uma vez que o turismo é um importante agente na complementação de renda e, consequentemente, na melhoria da qualidade de vida, porém, na presente circunstância em que o Assentamento se encontra, não é viável ainda o desenvolvimento do turismo, uma vez que a comunidade não está preparada para receber turistas, pelo fato de não deter conhecimento necessário acerca da atividade e por não possuir infraestrutura adequada para a recepção dos turistas e nem ter produção suficiente para atender aos mesmos. 
Portanto, vale ressaltar que a dimensão simbólica faz parte da atividade turística no meio rural, sobretudo suas particularidades, o que caracteriza a valorização do homem do campo, seus costumes, valores, tradições, além do potencial natural e cultural do assentamento, todos estes, vistos como os potenciais turísticos marcando o desenvolvimento da atividade no meio rural, porém, estes potenciais não são evidenciados nas políticas públicas, muito menos executados visando a uma mudança na realidade atual.

\section{Referências bibliográficas}

ALMEIDA, J.A.; RIEDL, M. Turismo rural: ecologia, lazer e desenvolvimento. Bauru: EDUSC, 2000.

ARAÚJO, J.G.F. ABC do turismo rural. Viçosa: Aprenda Fácil, 2000.

BARROS, A.J.S; LEHFELD, N.A.S. Fundamentos de metodologia científicas: um guia para a iniciação cientifica. São Paulo: Pearson Makron Books, 2000.

BENI, M. C. Análise estrutural do turismo. São Paulo: Senac, 2006.

BERGAMASCO, S.M.; NORDER, L.A.C. O que são assentamentos rurais. São Paulo: Brasiliense, 1996.

BIANCHINI, V. Políticas diferenciadas para a agricultura familiar: em busca do desenvolvimento rural sustentável. In: FILHO, F.B.B (ORG). Agricultura familiar a desenvolvimento territorial: contribuição ao debate. Brasília: Universidade de Brasília, Centro de Estudos Avançados Multidisciplinares, Núcleo de Estudos Avançados, 2005.

BRASIL. Ministério do Desenvolvimento Agrário. Secretaria da Agricultura Familiar. Pronaf. Disponível em: <http://comunidades.mda.gov.br/portal/saf/programas/ pronaf>. Acesso em 06 de maio de 2010.

BRASIL. Ministério do Desenvolvimento Agrário. Secretaria da Agricultura Familiar. Política Nacional de Assistência Técnica e Extensão Rural. Brasília: 2007. 26 p.

BRASIL. Ministério do Desenvolvimento Agrário. Programa Nacional de Turismo na Agricultura Familiar. Disponível em: <http://comunidades.mda.gov.br/dotlrn/clubs/ redestematicasdeater/turismonaagriculturafamilar/contents/photoflow-view/contentview?object $\mathrm{id}=874854$. 2003 > . Acesso 13 de maio de 2010.

BRASIL. Ministério do Desenvolvimento Agrário. Programa de Turismo Rural na Agricultura Familiar. Rede Turismo Rural na Agricultura Familiar - TRAF, Brasília: s/d. $28 \mathrm{p}$.

BRASIL. Ministério do Desenvolvimento Agrário. Territórios da Cidadania: proposta do Ministério do Desenvolvimento Agrário para a redução da desigualdade social no meio rural brasileiro. Disponível em: <http://www.cpact.embrapa.br/forum/11 $06 \quad 07 . p d f>$. Acesso em: 07 de outubro de 2010.

BRASIL. Ministério do Desenvolvimento Agrário. Secretaria de Reordenamento Agrário. Disponível em: <http://portal.mda.gov.br/portal/sra/programas/credito/2444650>. Acesso em: 18 de novembro de 2010. 
COELHO, E.M.B. Territórios em Confronto: a dinâmica da disputa pela terra entre índios e brancos no Maranhão. São Paulo: Huncitec, 2002.

DINIS, A. Para um turismo rural sustentável: empreendedorismo, estratégia de nicho e redes como fatores de preservação e inovação no meio rural. In: SOUZA, M.; ELES$B \tilde{A} O$, I. (ORGs). Turismo rural: iniciativas e inovações. Porto Alegre: Ed. Da UFRGS, 2011.

GIL, A. C. Como elaborar projetos de pesquisa. 4. ed. São Paulo: Atlas, 2009.

HAESBAERT, R.; LIMONAD, E. (1999) In.: O mito da desterritorialização: do "fim dos territórios" à multiterritorialidade. 6. Ed.Rio de Janeiro: Bertrand Brasil, 2011.

HOLANDA, F.A.B. Novo dicionário da língua portuguesa.Rio de Janeiro: Nova Fronteira, 1975.

INSTITUTO NACIONAL DE COLONIZAÇÃO E REFORMA AGRÁRIA. Terra Sol. Disponível em: <http://www.incra.gov.br> Acesso em: 07 de outubro de 2010.

MATTEI, L. Programa Nacional de Fortalecimento da Agricultura Familiar (PRONAF): concepção, abrangência e limites observados. In: IV Encontro da Sociedade Brasileira de Sistemas de Produção, 2001, Belém (PA). Anais do IV Encontro da SBSP, 2001.

MEDEIROS, L.S. Reforma agrária no Brasil: história e atualidade da luta pela terra. São Paulo: Editora Fundação Perseu Abramo, 2003.

REDE DE TURISMO RURAL NA AGRICULTURA FAMILIAR. Disponível em: <http:// www.redetraf.com.br/r-rede-traf.asp>. Acesso em 12 de maio de 2010.

ROSA, S.L.C. Agricultura Familiar e Desenvolvimento Local Sustentável. Foz do Iguaçu: SOBER, 1999.

SALLES, M.M.G. Turismo rural: inventário turístico no meio rural. Campinas: Alínea, 2003.

SCHNEIDER, S. As atividades não-agrícolas e as transformações do espaço rural: perspectivas recentes. Cap. 3 da Tese de Doutorado. Agricultura Familiar e Pluriatividade. Porto Alegre: UFRGS, 2003.

SEBRAE. Cartilha de acesso ao Pronaf: saiba como obter crédito para a agricultura familiar. s/d. $32 \mathrm{p}$.

SPOSITO, E. S. Geografia e filosofia: contribuições para o ensino do pensamento geográfico. São Paulo: Unesp, 2004.

VIEGAS, J. M. O turismo rural na agricultura familiar em Pernambuco.Um caminho a autonomia? A pluriatividade como uma ferramenta para o turismo solidário. Global Tourism, São Paulo, V. 3, n. 1, s/n, maio 2007.

VIEGAS, L. P. Possibilidades e limites de inserção do Assentamento Amaraji na atividade turística do Município de Rio Formoso-PE. 2006. Dissertação (Mestrado em Ciências Geográficas) - Universidade Federal de Pernambuco, Recife, 2006. 


\section{Nota:}

Território, como importante categoria da geografia, destacam Haesbaert e Limonad (1999), podem ser agrupadas sob três vertentes, são elas: a política, com aplicações nas relações de espaço-poder ou jurídico-política (espaço-poder institucionalizadas), unidade de atuação (não exclusiva) do Estado; a cultural, com aplicação na dimensão simbólica, produto de apropriação/valorização simbólica de um grupo em relação a seu espaço vivido (comunidades tradicionais), produto da ação coletiva e; a concepção econômica; fonte de recursos e/ou como unidade de construção de recursos específicos, desencadeando o embate entre classes sociais e relação capital-trabalho.

Rúbia Elza Martins de Souza: Universidade Federal de Rondônia, Porto Velho, RO, Brasil.

Email: rrubiaelza@bol.com.br

Link para o currículo Lattes: http://lattes.cnpq.br/8908741399671431

Luciana Pinheiro Viegas: Universidade do Estado de Mato Grosso, Nova Xavantina, MT, Brasil.

Email: lucianapviegas@yahoo.com.br

Link para o currículo Lattes: http://lattes.cnpq.br/2127221102593270

Data de submissão: 03 de junho de 2012

Data de recebimento de correções: 27 de dezembro de 2012

Data do aceite: 08 de abril de 2013

Avaliado anonimamente 